Supplement of Clim. Past, 13, 897-917, 2017

https://doi.org/10.5194/cp-13-897-2017-supplement

(c) Author(s) 2017. This work is distributed under

the Creative Commons Attribution 3.0 License.

(c) (1)

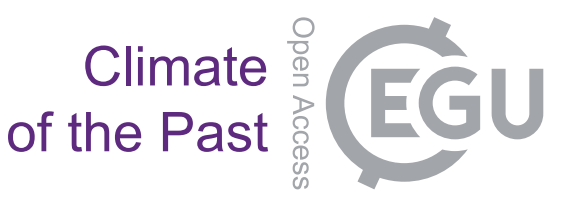

Supplement of

\title{
Periodic input of dust over the Eastern Carpathians during the Holocene linked with Saharan desertification and human impact
}

Jack Longman et al.

Correspondence to: Jack Longman (jack.longman@northumbria.ac.uk) and Daniel Veres (daniel.veres@ubbcluj.ro)

The copyright of individual parts of the supplement might differ from the CC BY 3.0 License. 

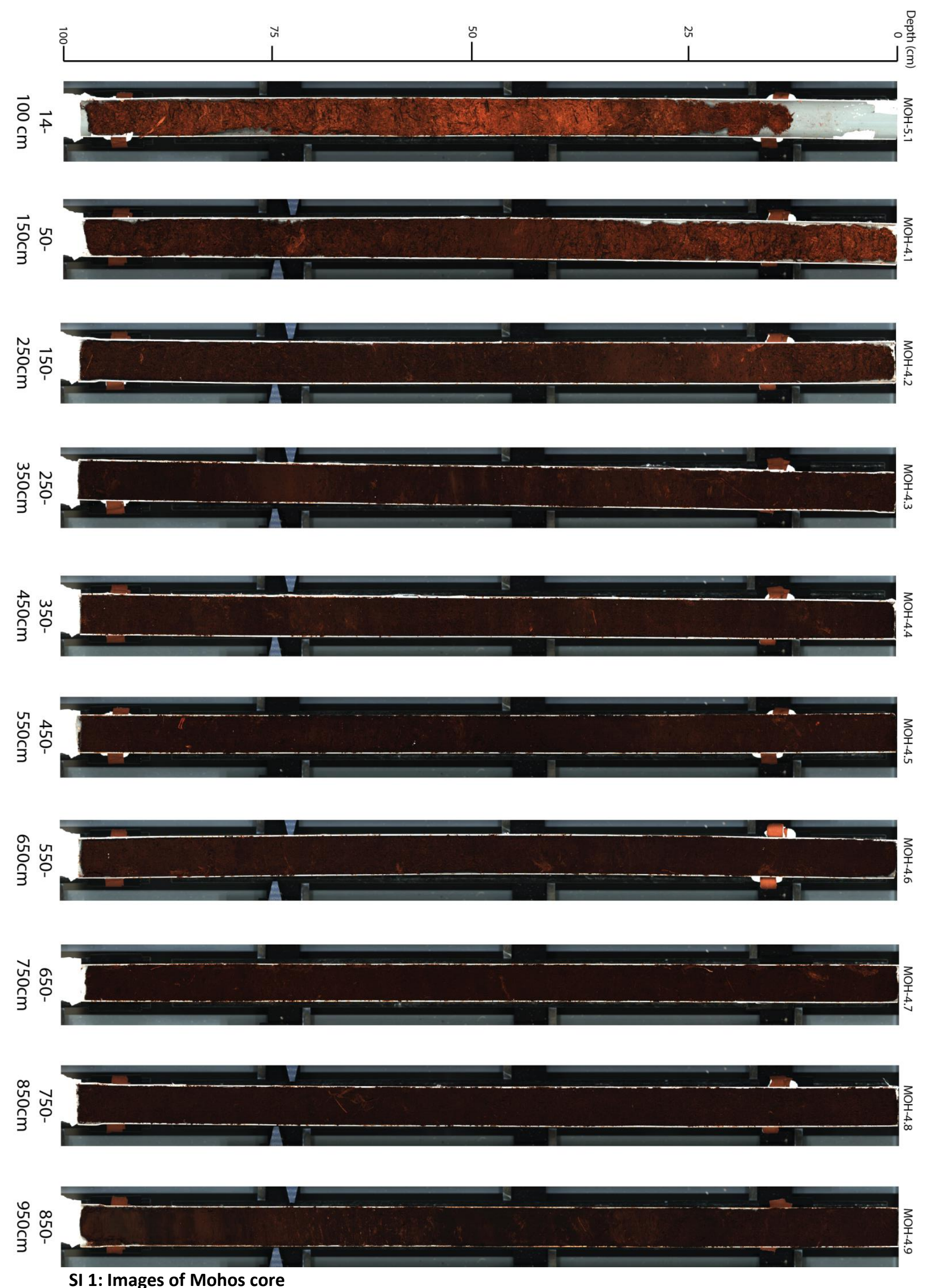

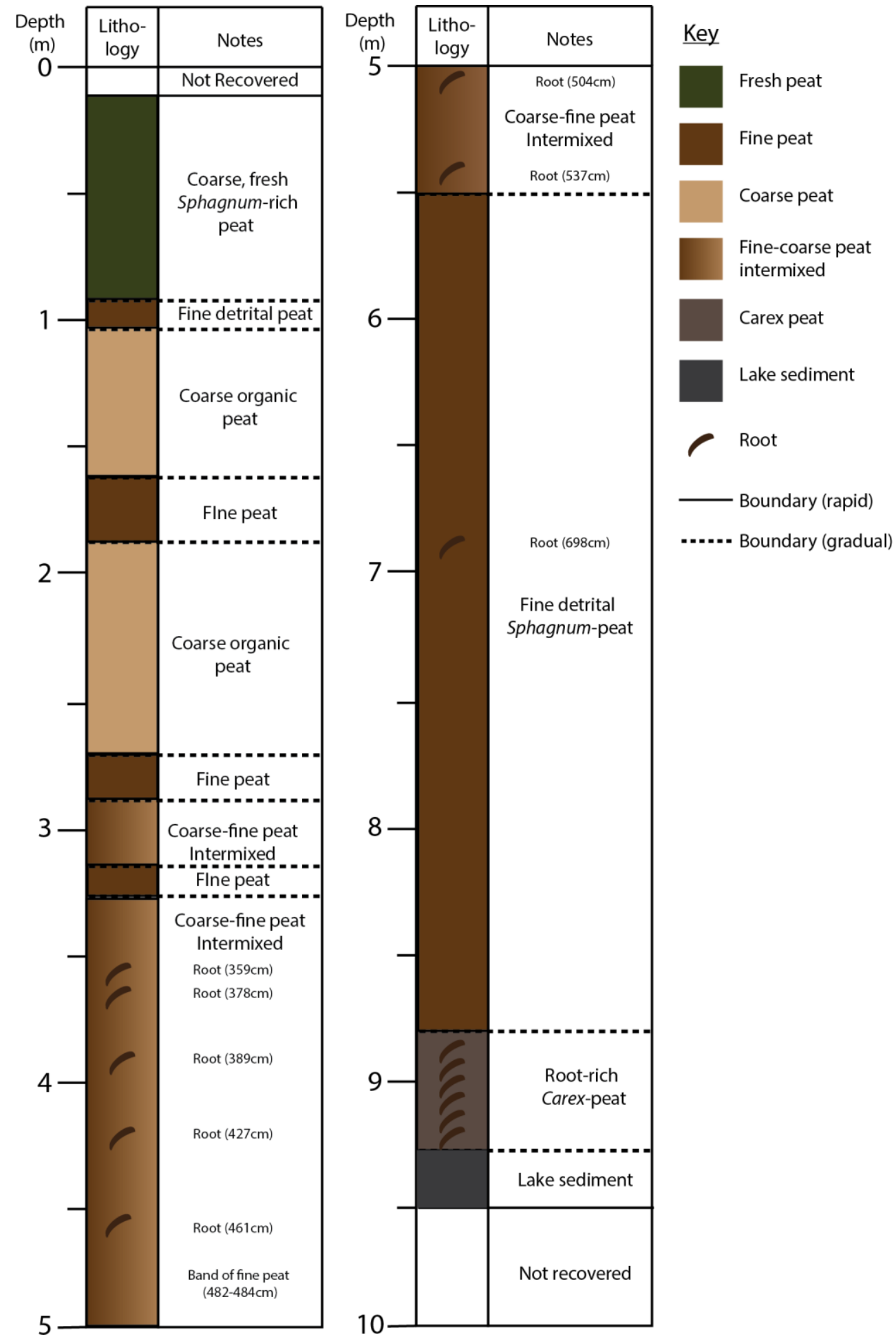

\section{SI 2: Lithological description of Mohos core}




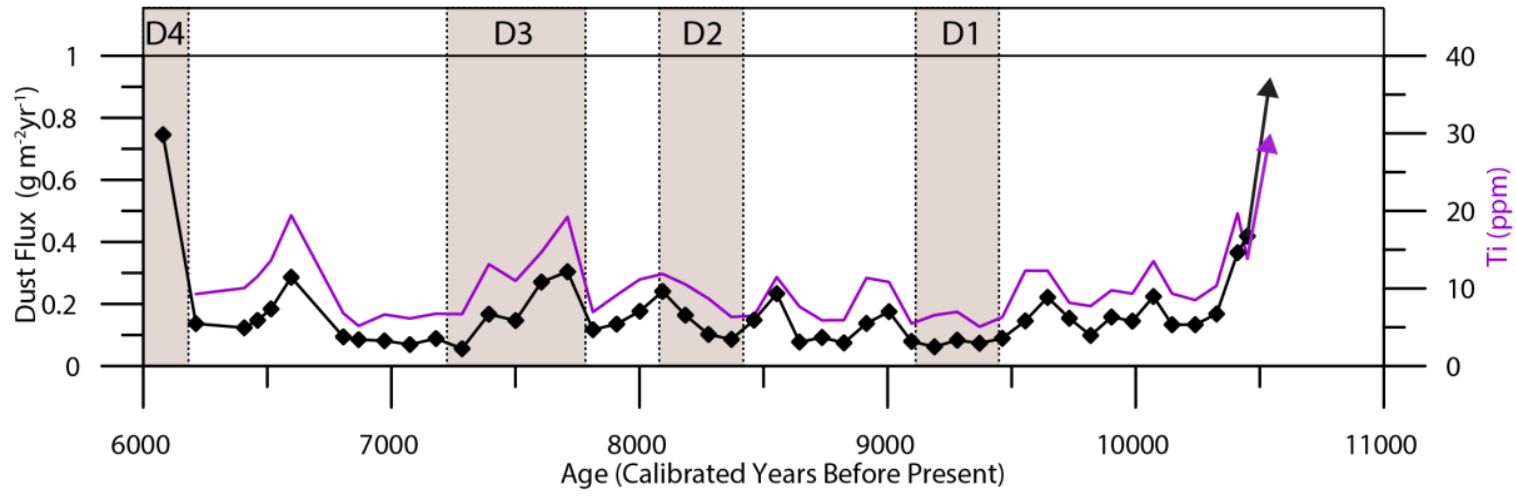

SI 3: Close-up of the dust flux and Ti ppm values for the period $10500-6000 \mathrm{yr}$ BP. Also presented are dust events identified within this time, and highlighted in brown. 


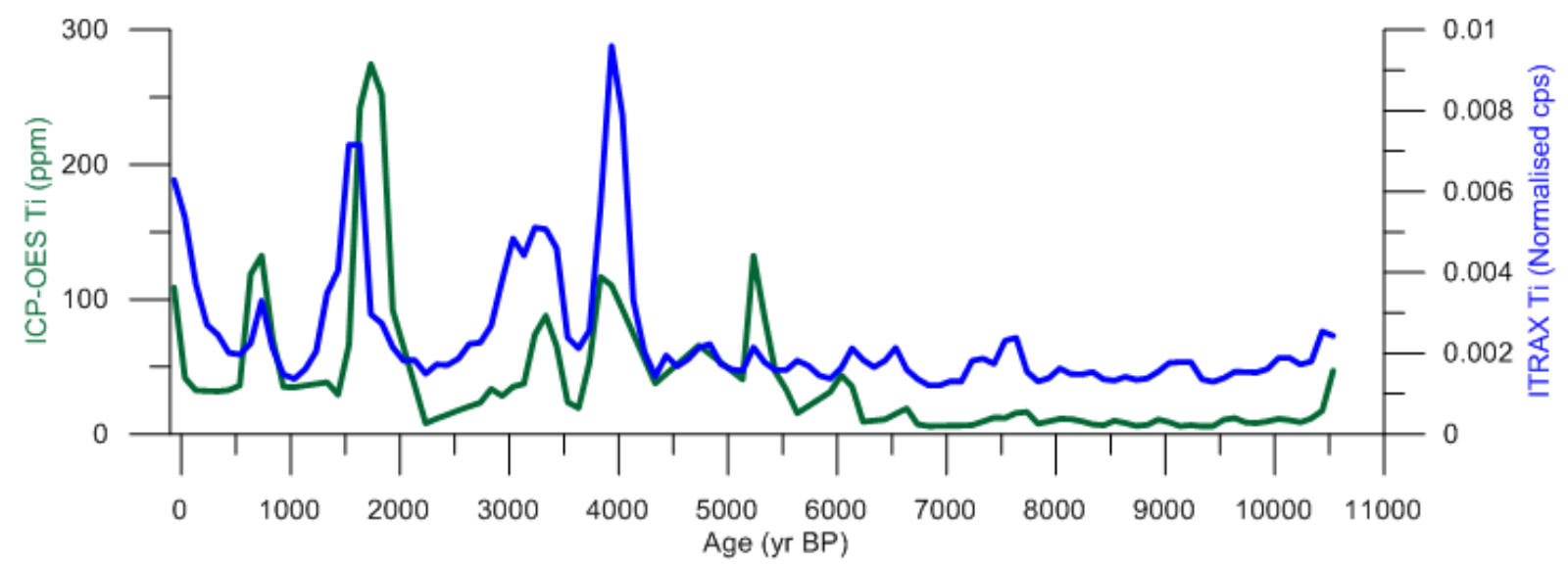

SI 4: Comparison graph of ICP-OES and ITRAX Ti data from Mohos core. To facilitate comparison, both data sets have been brought onto the same timescale via Gaussian interpolation at 100 year steps, using a 300-year window. 